Fixed Point Theory, 23(2022), No. 1, 163-178

DOI: $10.24193 /$ fpt-ro.2022.1.10

http://www.math.ubbcluj.ro/ nodeacj/sfptcj.html

\title{
ON COMPACTNESS AND FIXED POINT THEOREMS IN PARTIAL METRIC SPACES
}

\author{
DARIUSZ BUGAJEWSKI*, PIOTR MAĆKOWIAK** AND RUIDONG WANG*** \\ *Faculty of Mathematics and Computer Science, \\ Department of Nonlinear Analysis and Applied Topology, \\ Adam Mickiewicz University in Poznań, ul. Uniwersytetu Poznańskiego 4, \\ 61-614 Poznań, Poland \\ E-mail: ddbb@amu.edu.pl \\ ${ }^{* *}$ Faculty of Mathematics and Computer Science, \\ Department of Nonlinear Analysis and Applied Topology, \\ Adam Mickiewicz University in Poznań, ul. Uniwersytetu Poznańskiego 4, \\ 61-614 Poznań, Poland \\ E-mail: piotr.mackowiak@amu.edu.pl \\ ${ }^{* * *}$ College of Science, Tianjin University of Technology, \\ 300384 Tianjin, China \\ E-mail: wangruidong@tjut.edu.cn
}

\begin{abstract}
In this paper we examine two basic topological properties of partial metric spaces, namely compactness and completeness. Our main result claims that in these spaces compactness is equivalent to sequential compactness. We also show that Hausdorff compact partial metric spaces are metrizable. In the second part of this article we discuss the significance of bottom sets of partial metric spaces in fixed point theorems for mappings acting in these spaces.
\end{abstract}

Key Words and Phrases: Banach Contraction Principle, compactness, completeness, fixed point theorem, metrizability, partial metric spaces, sequential compactness.

2020 Mathematics Subject Classification: 54D30, 54E35, 54E50, 54H25.

\section{ACKNOWLEDGEMENT}

Ruidong Wang is grateful to the Faculty of Mathematics and Computer Science, Adam Mickiewicz University in Poznan, for the excellent working conditions during the visit from February 2018 to August 2018. Also this research was partly supported by the Natural Science Foundation of China (Grant Nos. 11201337, 11201338, 11371201, 11301384).

\section{REFERENCES}

[1] I. Altun, F. Sola, H. Simsek, Generalized contractions on partial metric spaces, Topology Appl., 157(2010), 2778-2785.

[2] M. Anisiu, V. Anisiu, On the characterization of partial metrics and quasimetrics, Fixed Point Theory, 17(2016), 37-46. 
[3] A.D. Arvanitakis, A proof of the generalized Banach contraction conjecture, Proc. Amer. Math. Soc., 131(2013), 3647-3656.

[4] D. Bugajewski, R. Wang, On the topology of partial metric spaces, Math. Slovaca, 70(2020), 135-146.

[5] J. Chaber, Conditions which imply compactness in countably compact spaces, Bull. Acad. Pol. Sci. Ser. Math., 24(1976), 993-998.

[6] K.P. Chi, E. Karapinar, T.D. Thanh, A generalized contraction principle in partial metric spaces, Math. Comput. Modelling, 55(2012), 1673-1681.

[7] S. Cobzaş, Fixed points and completeness in metric and in generalized metric spaces, J. Math. Sci., 250(2020), 475-535.

[8] R. Engelking, General Topology, Heldermann Verlag, Berlin, 1989.

[9] R.H. Haghi, Sh. Rezapour, N. Shahzad, Be careful on partial metric fixed point results, Topology Appl., 160(2013), 450-454.

[10] S. Han, J. Wu, D. Zhang, Properties and principles on partial metric spaces, Topology Appl., 230(2017), 77-98

[11] T.K. Hu, On a fixed-point theorem for metric spaces, Amer. Math. Month., 74(1967), 436-437.

[12] D. Ilić, V. Pavlović, V. Rakočević, Some new extensions of Banach's contraction principle to partial metric space, Appl. Math. Lett., 24(2011), 1326-1330.

[13] J.L. Kelley, General Topology, American Book Company, New York, 1969.

[14] S.G. Matthews, Partial metric topology, in: Papers on General Topology and Applications, Flushing, NY, 1992, in: Ann. New York Acad. Sci., vol.728, New York Acad. Sci., New York, 1994, 183-197.

[15] J. Merryfield, J.D. Stein Jr., A generalization of the Banach contraction principle, J. Math. Anal. Appl., 273(2002), 112-120.

Received: June 23, 2020; Accepted: April 9, 2021. 
